\title{
Ideological Manipulation in C-E Translation of the 13th Five-year Plan for Economic and Social Development of the People's Republic of China
}

\author{
Xue Jiang \\ School of Foreign Languages, North China Electric Power University, Changping District, Beijing, China \\ Shuo Zhao \\ School of Foreign Languages, North China Electric Power University, Changping District, Beijing, China

\begin{abstract}
The Manipulation School argues that the translation study should shift itself from the pure language level to a broader range such as political, cultural or social level. Among several parameters, ideology, poetics and patron are the most important three in manipulation theory. This paper tends to analyze the translation of the 13th Five-Year Plan for Economic and Social Development of the People's Republic of China under the perspective of ideology, which aims to prove the efficiency and feasibility of ideological manipulation for the translation of the 13th Five-Year Plan.
\end{abstract}

Index Terms-manipulation theory, ideology, the 13th Five-year plan, translation principle, translation strategy

\section{INTRODUCTION}

With the enhancement of China's comprehensive national power, China's international influence gradually rises. Therefore, more and more countries in the world begin to pay more attention to the fundamental policy and development direction of China's politics, economy, culture, society and so on. As the guiding ideology for the development of the five years (2016-2020), the 13th Five-Year Plan for Economic and Social Development of the People's Republic of China (the 13th Five-Year Plan for short) is not only the blueprint of China's economic and social development and an action plan for people of all nationalities together, but also the important basis of performing economic adjustment, market supervision, social management and public service of Chinese government. In addition, the analysis of any translated text must extend to contemporary social, cultural, political and ideological features (Mátyás B, 2015, p. 144). The link between language and ideology is central (Munday J, 2007, p. 198). This paper mainly discusses the translation of the 13th Five-Year Plan from the aspect of translated principles, translated strategies and so on under the manipulation of ideology, which aims to prove the efficiency and feasibility of ideological manipulation for the translation of the 13th Five-Year Plan. Firstly, this paper introduces the manipulation theory and the 13th Five-Year Plan simply. Secondly, it analyzes the translation of the 13th Five-Year Plan from the perspective of ideology manipulation theory. Finally, this paper gives brief summary of what has written above and a simple suggestion for future research.

\section{THEORY OF MANIPULATION}

In the past, people believed that the translators should not be visible during the translation. At the same time, translation should be based on the original document, reproduce the spirit and charm of the original works and fulfill the principle of equivalence and fidelity. In addition, translation is not only the power to shape literature, but also a principled means of text manipulation. The Manipulation School holds that the translation is a kind of "rewriting", that is to say, rewriting is manipulation, and translation is a means to serve power (Wei J. H., 2004, 29-32). The manipulation theory of Andre Lefevere expands the translation study from the pure document to the field of culture. Among several parameters, ideology, poetics and patron are the most important three in manipulation theory.

\section{A. The Manipulation of Patron}

There are many important factors during the process of translation, patron is the one of the most important parameters in the manipulation translation. Lefevere proposes that patronage refers to "something like the powers (persons, institutions) that can further or hinder the reading, writing, and rewriting of literature"(Lefevere A., 2010, p. 15). As an important political document of the government, the translation of the 13th Five-Year Plan must meet the government's will. That is to say, the government of China is the patron of the 13th Five-Year Plan and its translation.

\section{B. The Manipulation of Poetics}


Lefevere argues that poetics consists of two components, "One is the inventory of literary devices, genres, motifs, prototypical characters and situations, and symbols; the other is a concept of what the role of literature is, or should be, in the social system as a whole" (Lefevere A., 2010, p. 15). As one of the most important aspects of the manipulation theory, poetics requires that the translation should conform to the aesthetic of the English readers. Poetics could improve the acceptability of translation in the target language culture.

\section{The Manipulation of Ideology}

Ideology is a view of the world and society on a specific economic basis. For example, Philosophy, politics, law, art, religion and morality are all specific manifestations of human ideology (Li X. J., 2014, P.1566).Liu holds that ideology in Manipulation Theory refers to a type of belief, ideas or values that operates our behaviors. (Liu J., 2016, p.31). Ideology is regarded by Lefevere as the "grillwork of form, convention and belief which orders our actions" (Lefevere A., 2010, p. 16). There is a close connection between ideology and language. In any class society, language is a tool for the class to express and inculcate its ideology (Liu C. P., Chen J. H., 2015, pp. 91-94). Translation ideology "regards the ideology as a critical perspective, and shows the level of ideology in translation. The translator's translation strategies and translation result has a certain impact because of it" (Fang Y. L. 2013, pp. 202-206).In the process of translation, ideology manipulates the text by manipulating the translator. Therefore, lots of translation activities of the translator are controlled by ideology, because the translation is executed by the translators and all translators are guided by ideology. Language is an instrument for carrying class ideology. Therefore, translation will be influenced and manipulated by ideology because it is a tool of language transformation. In addition, as a tool of interlingual communication, translation is closely related to ideology. From the choice of translation, the choice of translator's translation strategy, the publication and distribution of translation to the acceptance and evaluation of translation, translation has been branded with ideology. Wang pointed out that in the process of translation, in addition to the dominant role played by the language operation platform, the implicit role of ideology also exerts pressure on translation (Wang D.F., 2003, pp.18-25). The effects of ideology during the translation are reflected in many aspects, such as the principles of translation, translation strategies and so on. All of these may be involved and applied in the process of translation.

\section{A BRIEF INTRODUCTION OF THE 13TH FIVE-YEAR PLAN}

The 13th Five-Year Plan for Economic and Social Development of the People's Republic of China was delivered in the Fifth Plenary Session of the 18th Communist Party of China Central Committee on October 29, 2015. The 13th Five-Year Plan not only outlines the bright prospects for China to build a moderately prosperous society in all respects in the future, but also will be an important force to the recovery of global economy. As one of the most influential and authoritative political documents, the 13th Five-Year Plan attracts great attention of people both at home and abroad. Foreign readers can better understand China's policies and measures such as political, economic, cultural, social and defense policies and measures. Hence, the translation of the 13th Five-Year Plan is as important as the original text. In the following chapters, this thesis intends to expound the effectiveness of the ideological manipulation theory in the process of the translation of the 13th Five-Year Plan.

\section{The Analysis of Ideological Manipulation in The Translated Version of 13Th Five-Year Plan}

Ideology is regarded by Lefevere as the "grillwork of form, convention and belief which orders our actions" (Lefevere A., 2010, p. 16). Translation, as a transmission activity of ideas or concepts, is also a representation of ideology, and its process is restricted or dominated by ideology (Lu S., 2008, pp. 46-48). In addition, translation is a kind of discourse, and the history marked by discourse should have a distinct ideological nature (Deng W.S, Zhang W.R., Zhang K., 2010, pp. 129-132). In this thesis, the translators should conform to the belief of China's government. That is to say, the translation of the 13th Five-Year Plan should obey the interests of China's government ideologically. Translation under the ideological manipulation is actually achieved through manipulation of the translator. Ideology promotes the creation of translation works by manipulating translators' choice of translation materials, selection of translation styles as well as the selection of translation principles and strategies.

The 13th Five-Year Plan is one of the most authoritative political documents in China, which involves politics, economy, culture, ecology and other aspects. Ideology not only manipulates the contents of the original texts of the 13th Five-Year Plan, but also manipulates the translation of form of it (Chang N.F., 2010, pp. 235-258). This thesis pays more attention to the translation of the 13th Five-Year Plan and the manipulation of ideology. Specifically speaking, this thesis analyzes the ideological manipulation in the translation of the 13th Five-Year Plan from the aspects of the principles of translation and translating strategies.

\section{A. Translators' Professional Literacy in the translation of the 13th Five-year Plan}

In most cases, translators' translation activities are under the control of ideology. In China, the ideology of the communist party of China inevitably influences all aspects of political and social life. Therefore, the communist party's ideology is also bound to influence the output of translated works. Although the text is translated directly by the translators, the translators must take the mainstream ideology into consideration. The translation of political texts is easy to touch the sensitive nerve of ideology, which requires translators to fully meet the requirements of ideology. In 
addition, translators should have profound scientific and cultural knowledge such as politics, economy, culture, history and so on so that they could understand the meaning of the original text accurately. To be exact, the translators are required to accurately restore the meaning of the original text under the manipulation of ideology by using his/her knowledge. There are two examples below in the translation of the 13th Five-Year Plan.

Example1：坚持不解纠正“四风”。

Translation: ......remain steadfast in the fight against formalism, bureaucratism, hedonism, and extravagance.

As the example shows, translators must fully understand the characteristics of Chinese political texts. Translators should know the connotation of abbreviations in political texts. The translators are required to know some background information about anti-corruption in China. For example, the translators should know that “四风” means formalism, bureaucratism, hedonism, and extravagance. The translators cannot accurately convey the meaning of the original text if he does not understand this basic knowledge.

Example2: 推进公铁水及航空多式联运。

Translation: We will advance the development of multi-modal transportation that integrates expressways, railways, waterways and airways.

In this translation of the example, it is difficult for foreign readers to understand what the “公铁水” means unless it is translated concretely. Therefore, the translators should translate the translation accurately on the basis of understanding the implied meaning of the original text. The translation of “expressways, railways, waterways" fully explains what “公 铁水” means, which avoids misleading and misunderstanding undoubtedly.

The two examples above show that it is necessary for translators to master the contents of the communist party's ideology as well as the basic knowledge of the political documents in China. Translation of political texts requires high professional quality of translators. Only by understanding the current social ideology and mastering the basic knowledge of the translation of political texts can translators get the translated job done successfully.

\section{B. The Adoption of Translation Principles under the Influence of Ideology}

At the micro level, the ideology influences on the level of linguistics, such as the choice of translating principle and translating strategy. In the process of the translation of the 13th Five-Year Plan, the translating principles used by translators are not arbitrary. The application of the translating principles should obey the dominant ideology of China. In other word, the translators must translate the 13th Five-Year Plan accurately, instead of any subtracting, adding, distorting or derivation to the 13th Five-Year Plan. Translators are not allowed to violate the prevailing ideology when they use certain principles. There are three principles here.

1. The Principle of Accuracy

In the translation of 13th Five-Year Plan, there is a much more rigorous standard of fidelity. It is due to the fact that the political constitution involves major national policies, basic policies, etc. If the translation is wrong, the consequences will be serious (Cheng Z. Q., 2003, pp.20-24). The translation of any political documents is more politically sensitive than the translation of other genres. Compared to other principles, there is no doubt that the principle of accuracy is the first and most important one when translators translate the 13th Five-Year Plan. The translators are not allowed to make such mistakes as changes and ambiguity of the source text. Accuracy is not confined to the linguistic level, but also manipulates the translation to adhere to the prevailing ideology of the original context. There are some examples in the translation of the 13th Five-Year Plan.

Example3: 提高行政效能, 激发市场活力和社会创造力。

Translation: ....., so as to refine government performance and stipulate market vitality and social creativity.

Instead of using words like “improve" or “increase", the translators choose to translate the expression “提高行政效 能” into "refine government performance" in example 3. Ideology requires translators to translate texts accurately and there should not be any ambiguities. The word "improve" or "increase" may give foreign readers the impression that the Chinese government is inefficient before. However, the expression “提高行政效能” in the 13th Five-Year Plan just aims to make the performance of Chinese government more excellent other than implies that the government is incompetent. Under the manipulation of this ideology, the word "refine" is more appropriate to express the meaning of the original text.

Example 4: 发挥科技创新在全面创新中的引领作用。

Translation: We will see that scientific and technological innovation leads the way in all areas of innovation.

In example 4, there is no subject in the sentence, which is common enough in Chinese because Chinese tends to omit the subject. While in the translation of the 13th Five-Year Plan, the subject "we" is added in this sentence by the translators. On the one hand, the English version of the 13th Five-Year Plan should be consistent with English expression habits. To be exact, it is customary to specify the subject in English expressions. On the other hand, the addition of the subject "we" could help the translation version be more accurate. Under the manipulation of ideology in China, the word "we" represents the Chinese government. It could indicate that Chinese government will try its best to take positive measures in terms of scientific and technological innovation. Therefore, the addition of the subject "we" is in full accord with contemporary ideology.

2. Readability and Comprehensibility 
It is well known that the translation is designed to make it easier for people with different languages to communicate with each other. Therefore, accuracy is not enough for the English version of the 13th Five-Year Plan. Readability and comprehensibility are very important and indispensable for a good translation because the translation of 13th Five-Year Plan is to disseminate Chinese policy of politics, economy, culture and so on. Through reading the translation of 13th Five-Year Plan, foreign readers could know the policies and objectives of contemporary China. As a result, the translation of 13th Five-Year Plan must be readable and comprehensible to serve the aim of communication. This requires the translators to follow the rules of English grammar and change the original text slightly when necessary to avoid ambiguity and misreading. Please have a look at the examples below.

Example5: 秉持亲诚惠容, 坚持共商共建共享原则。

Translation: We will uphold amity, sincerity, mutual benefit, and inclusiveness as well as the principle of joint discussion, common development, and shared growth.

In the translation of this example, there are Chinese four-character forms. Let's take “亲诚惠容” for example. The translators translate the “亲诚惠容” into “amity, sincerity, mutual benefit, and inclusiveness”, which fully explains the original one to the foreign readers. Each word in Chinese represents a certain meaning correspondingly. If the translators do not explain the implied meaning, the foreign readers may not understand this Chinese four-character form well. On the premise of not violating the original meaning, it is very important to add the necessary information in the translation and explain it to make foreign readers understand.

Example6: 支持共建大珠三角优质生活圈。

Translation: We will support joint efforts by Guangdong, Hong Kong, and Macao to build a quality living area in the Greater Pearl River Delta region.

In the example above, the meaning of the Greater Pearl River Delta is well-known to Chinese people, but the translators still need to add background to explain the Greater Pearl River Delta region for foreign readers, which is a generic terms of Guangdong, Hong Kong, and Macao. Because the translation aims to help people who use different languages to communicate with each other and know each other, the translators must take the readability and comprehensibility of the translation into account. It is necessary for the translators to further explain the Greater Pearl River Delta region, because there are few foreign readers could understand this expression in a correct way. Such translation not only conforms to the habit of English expression, but also effectively conveys the meaning of the original text. Translators eliminate the reading barriers of foreign readers and enhance the readability and comprehensibility of the translation of the 13th Five-Year Plan. The translated text can help foreign readers better understand the content of the 13th Five-Year Plan.

The two examples above show that the principle of accuracy is not the only requirement in the translation of political documents. Good translation is for communication, which is inseparable from understanding each other. Under the principle of readability and comprehensibility, the translators should not only pursue the equivalence between the original text and the translated version, but take the understanding of foreign readers into account. That is to say, in addition to considering the accuracy of the translation of 13th Five-Year Plan, translators should also pay attention to the acceptance level of the foreign readers for the aim of multinational communication.

3. Avoidance of Repetitious Words

In the process of translation, translators are likely to deal with the repetitious information in the source language. Improper handling will lead to Chinglish because it does not conform to English habits. The translators should make proper translation omission, which requires the translation version conform to the thinking habits of the audience, and to deal with the repetition of Chinese-English translation correctly. According to the expression habit of Chinese, there will be many expressions that have different forms but the same meaning. English speakers, however, tend to express things in plain and simple language. In order to make the translation more accurate, precise and professional, it is necessary to delete all kinds of repetition in the process of Chinese-English translation of the 13th Five-Year Plan. There are several examples in the document.

Example7: 深化行政审批制度改革，最大限度减少政府对企业经营的干预，最大限度缩减政府审批范围。

Translation: We will deepen reform of the government review and approval system, reducing to the greatest possible extent government intervention in enterprises as well as the scope of the government pre-approval system.

In the Chinese original sentence, “减少” and “缩减” appear at the same time in order to make the Chinese sentence more professional. However, the translator only uses the present participle form of "reduce" to substitute to the two words “减少” and “缩减” in the translated version. It does not affect the meaning to be expressed in the original text. On the contrary, this translation method better conveys the meaning of the original text. The translation accords with the reading custom of foreign readers and enhances the readability of the article. It can be seen from this example that due to the different expressive habits of Chinese and English, translators need to adopt the method of translation omission when it is necessary to avoid repetition in the target language culture.

Example8: 推动与周边国家基础设施互联互通。

Translation: We will increase infrastructure connectivity with neighboring countries.

In this Chinese example, “互联互通” is a structure that conforms to Chinese usage. It means "connect and communicate with each other", but in English it is a repetitious structure of a sentence and does not conform to the 
idiomatic expression of English. Therefore, in the process of the Chinese to English translation, it is obvious that “互联 互通" has been translated into one word "connectivity" in order to avoid repetition.

Example9: 构建官民并举、多方参与的人文交流机制。

Translation: We will create mechanisms for official and nongovernmental cultural exchanges that involve the participation of multiple parties.

Here “并举” is not translated into the English version by the translators. There is no doubt that “并举” in the original is a supplement part, which is in line with the expression habits of Chinese. But this kind of expression is repetitious in English, thus it will cause sentence repetition to some extent, which is generally not adopted in English. Because the omission of “并举” does not affect the overall sentence structure and sentence meaning, the translators omit it in the translated version. The omission of repetitious words is more acceptable to foreign readers. The aim is to bring the expression closer to the idiomatic usage of English without changing the original meaning.

The examples above show that ideology requires not only the accuracy and readability of translation, but also the proper use of abbreviated translation methods. It can make the translation more in line with the reading habits of target language readers, so that they can better understand China's policy measures of politics, economy, culture, education, national defense and other aspects.

\section{The Application of Translation Strategies with the Impact of Ideology}

In this part, the author tends to analyze the translation of the 13th Five-Year Plan from the aspects of translation strategies. Two translation strategies are introduced in the following part. It is dependent on what the purpose is of translation of the 13th Five-Year Plan under the manipulation of the dominating ideology when the translators pick them.

\section{Foreignization}

Foreignization refers to the use of the original expression in the translation process, so that the translation is full of exotic atmosphere. It focuses on the differences of national culture and aims to preserve and reflect the national characteristics and linguistic styles of foreign countries. Foreignization can fully reflect the diversity of culture and facilitate the exchange and learning between different cultures. To preserve as much of its original flavor as possible in the process of translation of the 13th Five-Year Plan, there are many examples of the using of foreignization.

Here are several examples below. These are all expressions with Chinese characteristics and use foreignization translation strategies to retain the original flavor of Chinese expressions.

Example 10: 建设新疆丝绸之路经济带核心区。

Translation: We will work to develop Xinjiang as the core region for the Silk Road Economic Belt.

Example 11: 发挥妈祖文化等民间文化的积极作用。

Translation: .......give full expression to the positive role of folk cultures such as Mazu culture.

Chinese has many culture-loaded expressions which need to be translated without any changes. That is to say, some expressions with Chinese characteristics should be translated literally under the guidance of foreignization translation strategies. It is helpful to reserve the original flavor in the translated version. Here “丝绸之路经济带” and “妈祖文化” are respectively translated into "the Silk Road Economic Belt" and "Mazu culture" literally, which fully retains the charm of the expression with Chinese characteristics.

Example 12: 促进全球贸易投资的自由化和便利化。

Translation: We will help promote the liberalization and facilitation of international trade.

“......化” is a usage with Chinese characteristic and there is no such homologous expression in English. “自由化” and “便利化” here are translated into "liberalization" and "facilitation" respectively, which intends to demonstrate the support of China's government towards the international trade. The strategy in the translation could make the translation more acceptable to foreign readers. There is no doubt that the strategy of foreignization is indispensable.

2. Domestication

In contrast with foreignization, the so-called domestication translation requires the translators to be close to the target language reader and adopt the target language expression method that readers are accustomed to in order to convey the content of the original text. The proper use of domestication in translation can achieve image reconstruction and help readers to have the maximum resonance with the readers of the source language. When the foreignization translation strategy can't handle the original text well, the translators can try it by adopting the domesticating translation strategy. Please read the following examples.

Example 13: ......畅通海上贸易通道。

Translation: .......maritime trade routes are clear and free-flowing.

There is no doubt that it is an important criterion to evaluate the quality of translated works whether the target readers could fully understand the translation or not. In order to help foreign readers to understand and appreciate the translated version thoroughly, the translators need to explain the difficult words in the translation. Here “畅通” in the original sentence has been translated in another way so as to expound the original meaning for the foreign readers. It is obvious that the strategy of domestication is applied in the translation here.

Example 14: 强化社会监督。 
Translation: We will sure that public oversight is strengthened.

It is common to omit the subject in Chinese as the example shows above. In order to make the sentence more accurate and fluent, the translators add the main clause "We will sure that" into the translation of this sentence. The added part demonstrates China pays high attention to the public oversight. This example shows that the translators domesticate the structure of this sentence in order to make the translation of the 13th Five-Year Plan more readable.

\section{CONCLUSION}

In conclusion, translation is a dynamic and complex process, which is dominated and manipulated by ideology. Under the influence of the manipulation theory of Lefevere, especially his ideology manipulation theory, this thesis analyzes the translation of the 13th Five-Year Plan smoothly. The thesis chooses to analyze the translation of the 13th Five-Year Plan from the ideological manipulation aspect, which not only proves the efficiency and feasibility of ideological manipulation for the translation of the 13th Five-Year Plan but also demonstrates that the ideological manipulation will exert influence on the choices of the translated principles and translated strategies of the translators. The ideological manipulation requires that translators should ensure accurate transmission of information and make sure that readers can accept it.

\section{REFERENCES}

[1] Chang N.F. (2010). Faithfulness, Manipulation, and Ideology: A Descriptive Study of Chinese Translation Tradition. Perspective: Studies in Translatology, 6:2, 235-258.

[2] Cheng Z. Q. (2003). Political Angle in the Translation of Political Articles. Chinese Translators Journal, 03, $20-24$.

[3] Deng W.S., Zhang W.R., Zhang K. (2010). On the Relationship between Ideology and Translator - Take Liang Qichao's Translation of Byron as an Example. Journal of Lanzhou University (Social Sciences), 38(S1), 129-132.

[4] Fang Y. L. (2013). Translated ideology and ideological translation - an investigation of "ideology" in translation studies. Journal of Southwest University for Nationalities (humanities and social sciences), 5, 202-206.

[5] Mátyás B. (2015).Translation and Political Discourse. Acta Universitatis Sapientiae, Philologica, 2, 139-158.

[6] Munday J. (2007). Translation and Ideology. The Translator, 2, 195-217.

[7] Lefevere, A. (2010). Translation, Rewriting and Manipulation of Literary Fame. Shanghai: Foreign Language Education Press.

[8] Li X. J. (2014). The Modern Chinese Standard Dictionary ( $3^{\text {rd }}$ Edition). Beijing: Foreign Language Teaching and Research Press.

[9] Liu C. P., Chen J. H. (2015). Untranslatability and ideological manipulation of translation. Shanghai Journal of Translators, 3 , 91-94.

[10] Liu J. (2016). On the C-E Translation of Political Texts from the Perspective of Manipulation Theory-A Case Study of the Government Work Report 2014. Dongbei University of Finance and Economics. China.

[11] Lu S. (2008). The Ideology of Translation from the Perspective of Intertextuality. Foreign Languages and Their Teaching, 12, 46-48.

[12] Sun L. (2012). The Ideological Manipulation in the Political Document Translation: -A Case Study. Yangtze University, China.

[13] Wang D.F. (2003). An Invisible Hand - on the Manipulation of Ideology in Translation Practice. Chinese Translators Journal, 5, 18-25.

[14] Wei J. H. (2004). A Comprehensive View of Manipulation School Translation Theory. Journal of Guangdong University of Foreign Studies.3, 29-32.

Xue Jiang was born in Nei Mongol, China. She is an Associate Professor in the School of Foreign Languages, North China Electric Power University, Beijing, China. Her research interests cover Translatology, Cognitive Linguistics and Foreign Language Teaching.

Shuo Zhao was born in Hebei, China. She is currently a master student in the School of Foreign Languages, North China Electric Power University, Beijing, China. Her research interest is mainly translatology. 